\title{
Detection of Malaria Parasites in Mosquitoes from the Malaria-Endemic Area of Chakaria, Bangladesh
}

\author{
Akter Tangin, ${ }^{a}$ Yuka Komichi, ${ }^{a}$ Yukiko Wagatsuma, ${ }^{b}$ Haque Rashidul, ${ }^{c}$ Yusuke Wataya, ${ }^{a}$ and \\ Hye-Sook $\mathrm{KIM}^{*, a}$ \\ ${ }^{a}$ Faculty of Pharmaceutical Sciences, Okayama University; Tsushima, Okayama 700-8530, Japan: ${ }^{b}$ Graduate School of \\ Comprehensive Human Sciences, University of Tsukuba; Ibaraki 305-8575, Japan: and ${ }^{c}$ Centre for Health and Population \\ Research, ICDDR, B; Mohakhali, Dhaka-1212, Bangladesh. \\ Received December 1, 2007; accepted January 4, 2008; published online February 4, 2008
}

\begin{abstract}
Malaria is one of the major public health problems of Bangladesh. We investigated the mosquito populations infected with malaria parasites in a malaria-endemic area Chakaria, Bangladesh, where Anopheles dirus and Anopheles minimus are the principal vectors. Anopheles mosquitoes were collected with a CDC miniature light trap from inside households in June 2007. A total of 868 mosquitoes were collected, among which females numbered 669 (77.1\%). The species of female Anopheles mosquitoes were identified morphologically, and 651 were $A$. minimus and the remaining 18 were other Anopheles species. Malaria parasite DNA from individual female mosquitoes was extracted and distinguished using the microtiter plate hybridization (MPH) technique targeting the 18S rRNA of human malaria parasites. Nineteen mosquitoes were malaria parasite positive: 12 for Plasmodium falciparum, 1 for Plasmodium vivax, and 6 for both $P$. falciparum and $P$. vivax. This is the first time that the MPH technique was used for distinguishing malaria parasites in mosquitoes and the first report from Chakaria. Our results may contribute to planning and assessing malaria control strategies in Chakaria.
\end{abstract}

Key words malaria; Anopheles; polymerase chain reaction; microtiter plate hybridization

Malaria is caused by the protozoan parasite of the genus Plasmodium which is transmitted to humans when female Anopheles mosquitoes feed on an infected host. ${ }^{1)}$ It has become one of the biggest health concerns in Bangladesh. ${ }^{2}$ Malaria disappeared from the plains after an eradication campaign with dichloro-diphenyl-trichloroethane (DDT) from $1961-1976^{3,4)}$ but slowly spread again with migration. Thirteen of the 64 districts on the northern and eastern borders are seriously affected by malaria. Reported clinical cases numbered 378000 , laboratory-confirmed cases reached 60000 , and deaths totaled 528 in 1998. ${ }^{5}$ The most cases of malaria are found in the three districts of the Chittagong Hill Tracts bordering India and Myanmar, and Plasmodium falciparum is the predominant species.) ${ }^{6}$ In Chakaria, which is under the division of Chittagong, there was communitybased surveillance in 2002 which detected 1543 clinical cases. $^{7)}$

Malaria distribution is usually determined by the presence of its mosquito vector. Climatic factors such as humidity, rainfall, and temperature control the development of both malaria parasites and vectors. ${ }^{2)}$ Four hundred anopheline species are distributed worldwide; only 40 are important malaria vectors. ${ }^{8)}$ In Bangladesh, 34 Anopheles species have been recorded and among them the four species Anopheles dirus, Anopheles philippinensis, Anopheles sundaicus, and Anopheles minimus are considered important malaria vectors. $^{9,10)}$ Among these species, $A$. dirus and $A$. minimus are the most widespread, are known to be forest-related vectors, and can expand their range under favorable conditions such as the monsoon period. ${ }^{5)}$

Malaria transmission ultimately depends upon the sporozoite rate of mosquitoes, ${ }^{11)}$ and determining the presence of malaria sporozoites in Anopheles mosquitoes caught in the wild is an important factor in epidemiologic studies of malaria-endemic areas. ${ }^{12)}$ The standard method for detection of malaria sporozoites in mosquito salivary glands uses light microscopy. Specimens must be dissected when fresh, and examination of individual mosquitoes is time-consuming and labor intensive. ${ }^{13,14)}$ In recent years, the polymerase chain reaction (PCR) has been used to amplify the specific DNA sequences of $P$. falciparum for highly sensitive detection of parasites in the mosquitoes. ${ }^{14,15)}$ In most cases, the target sequence used for detecting malaria parasites in mosquitoes using PCR is the Plasmodium species-specific small subunit ribosomal RNA (SSUrRNA). ${ }^{13,16,17)}$ On the other hand, it is sometimes difficult to detect parasites in blood-engorged mosquitoes using the PCR method, ${ }^{18)}$ because mosquito extracts contain strong PCR inhibitors that prohibit amplification of parasitic DNA in mosquito vectors. ${ }^{19)}$

Previously, we developed the microtiter plate hybridization (MPH) technique, which is a combination of PCR amplification targeting the $18 \mathrm{~S}$ rRNA of human malaria parasites and DNA hybridization. The MPH technique not only detects the malaria parasites but also can distinguish the different human malaria parasite species. Our technique is simple, highly sensitive, and specific for human malaria parasites and has already been used for human malaria parasite diagnosis in the Solomon Islands, ${ }^{20)}$ Vietnam, ${ }^{21)}$ Thailand, ${ }^{22)}$ and Korea. ${ }^{23)}$ Few data are available on the natural transmission of malaria, in particular mosquito bionomics and the infectivity of the malaria vectors occurring in the Chittagong division, Bangladesh. The aim of our study was to determine the infection rate and distinguish different Plasmodium species in the mosquitoes in a malaria-endemic area in Bangladesh using the MPH technique. To the best of our knowledge, this was the first time that the PCR-based MPH technique was used to detect and distinguish malaria parasite species infection in Anopheles mosquitoes.

\section{MATERIALS AND METHODS}

Study Area The study was conducted in Chakaria, 


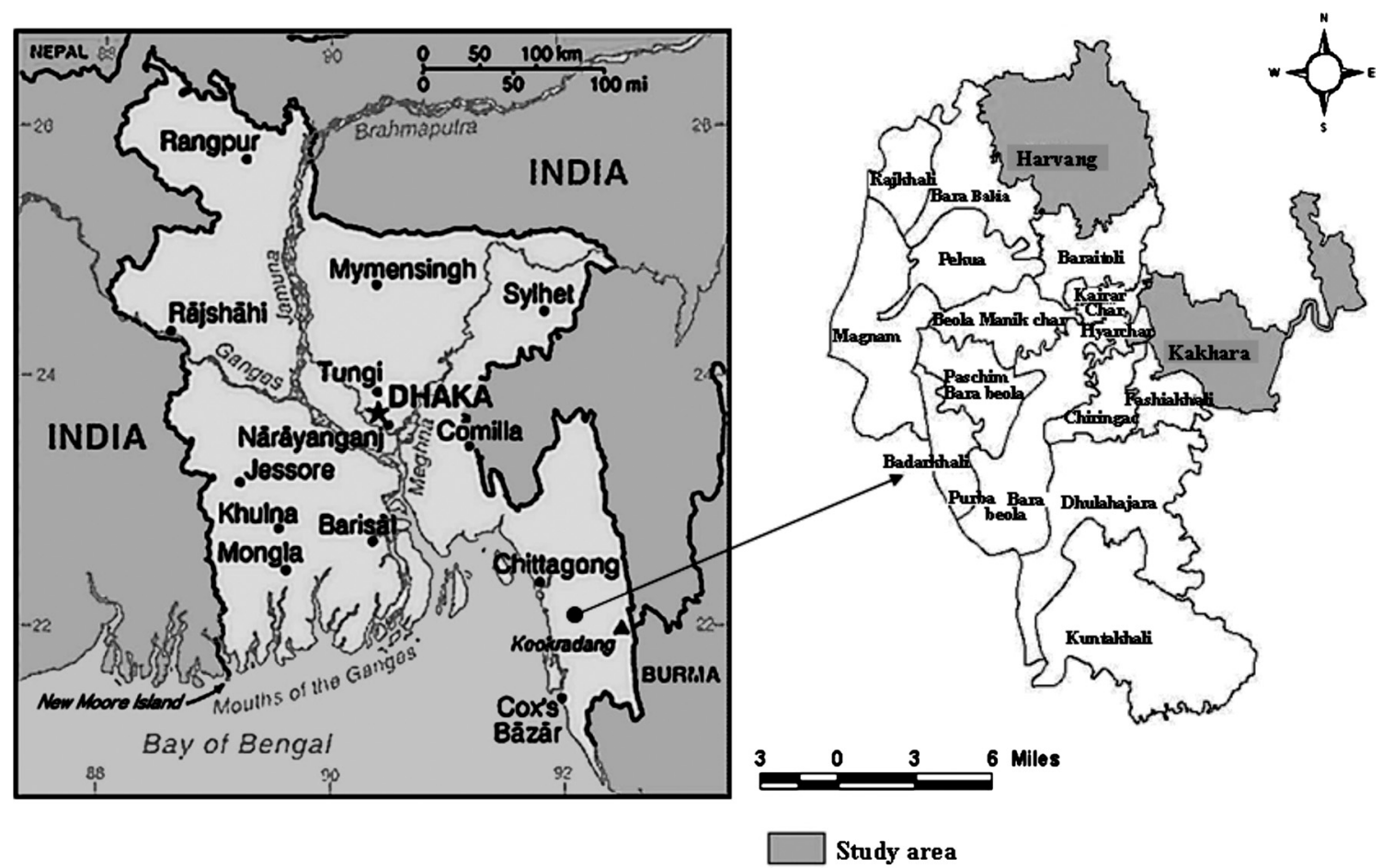

Fig. 1. Map of the Study Area Chakaria, Bangladesh, Where Mosquitoes Were Collected

Bangladesh, and the protocol was approved by the International Centre for Diarrhoeal Disease Research, Bangladesh (ICDDR, B). Chakaria is a subdivision in the district of Cox's Bazaar under the division of Chittagong. It has a population of 550000 with an area of $643.46 \mathrm{~km}^{2}$, and is surrounded by many rivers such as the Matamuhuri, Maheshkhali, and $\mathrm{Ku}$ tubdia Channel (Fig. 1). The east side of the Chakaria area is hilly with forests, and the west side is low lands bound by the Bay of Bengal. Two unions (Kakara and Harvang) of Chakaria were selected for mosquito collection. Traditionally, the main economic activities in the area have been agriculture, forestry, and fishing. Most of the people are very poor, wear very scanty clothes, and are exposed to the vector as they live in houses that sometimes have one or more side open. Household walls are usually made of bamboo and mud and very few are made of tin, wood, or cement; floors are earthen; roofs are made of leaves and straw and very few are of tin. The domesticated animals are cows, goats, and chickens that live in the areas surrounding houses. Cattle sheds are open without walls and located adjacent to households. The climate of Chakaria from May to September is characterized by heat and heavy rainfall, while the remainder of the year is mostly dry. The annual maximum temperature is $28-29^{\circ} \mathrm{C}$ and the minimum temperature is $20-21^{\circ} \mathrm{C}$. Most rain occurs during the monsoon (June-September) and little in winter (November-February); annual rainfall is 3000 $3500 \mathrm{~mm}$. During the study period in June 2007, there was heavy rainfall of $425 \mathrm{~mm} / \mathrm{d}$ in Chittagong division, and flooding made two-thirds of the area unreachable.

Mosquito Collection Adult mosquito collection was carried out June $12-30,2007$, just after the heavy rainfall. The mosquitoes were collected using six standard miniature CDC light traps (Model 512; John W. Hock Company, Gainesville, Florida, U.S.A.). In Chakaria, mosquitoes were collected from the three villages Goalmara, Pahartoli, and Manikpur in two unions upon receiving consent from the household heads. People living in these houses were protected with nonimpregnated bed nets. The trap was hung inside the room of sleeping persons as described previously. ${ }^{24)}$ The light traps were switched on each day at 18:00 and were collected at 06:00 of the next morning.

The captured mosquitoes were transported to the laboratory in plastic containers inside desiccators over silica gel. They were then separated into Culicinae and Anophelinae and counted. The individual female Anopheles mosquitoes were identified based on the taxonomic keys and stored in tubes inside the desiccators over silica gel until completely dry. The mosquitoes were stored under the same conditions until transported to the main laboratory, where they were stored at $-80^{\circ} \mathrm{C}$ until processed for DNA extraction.

Extraction of Malaria Parasite DNA from Mosquitoes DNA was extracted from the individual mosquitoes with MX-16 DNA purification kits (Promega, U.S.A.) that were used with the MX-16 instrument to provide an easy method for efficient automated purification of genomic DNA from solid biomaterials. This system is based on magnetic bead technology and composed of a magnetic bar, bore, and purified cartridge. In this system, the movement of the bore is controlled by motors, which allows easy DNA extraction from crude lysate magnetic beads. All the necessary reagents for purification of nucleic acid from a single mosquito are supplied in one reagent cartridge. Each well of the cartridge is prefilled with magnetic beads, wash buffer (I, GuSCN $5.25 \mathrm{M}$; II, 70\% EtOH), and lysis buffer (GuSCN $\left.4.7 \mathrm{M}){ }^{25}\right)$ The DNA isolation was performed by adding sample into the lysis chamber. The procedures for DNA purification was performed automatically, and after DNA extraction it was transferred to a fresh tube and stored at $-80^{\circ} \mathrm{C}$ until use. 
Target Sequences of Malaria Parasites The oligonuleotide primer set, biotin-labeled MPH1 of 5'-CAGATACCGTCGTAATCTTA-3' and MPH2 of $5^{\prime}$-CCAAAGACTTTGATTTCTCAT-3', which are specific to the 18Sr RNA genes of the human malaria parasites of $P$. falciparum and Plasmodium vivax, Plasmodium ovale, Plasmodium ovalevariant, and Plasmodium malariae were described previously. ${ }^{20,23,26)}$ These two primers were used for the DNA amplification of the malaria parasites in mosquitoes with PCR. After PCR amplification, the PCR products were used to distinguish the malaria parasite species using the MPH technique. The specific probes of $P$. falciparum $5^{\prime}$-GTCACCTCGAAAGATGACTT-3', $P$. vivax 5'-TAAACTCCGAAGAGAAAATTC-3', $P$. ovale 5'-AATTTCCCCGAAAGGAATTTTC-3', $P$. ovale-variant $5^{\prime}$-GAAATTTCCAAAGGAATTTTC-3', and $P$. malariae 5'-ACTCATATATAAGAATGTCTC- $3^{\prime}$ were captured in the microtiter plate as described previously. ${ }^{21,27)}$

Preparation of DNA for PCR Five microliters of extracted DNA from Anopheles mosquitoes was added to the $0.2 \mathrm{ml}$ microcentrifuge tube containing $40 \mu \mathrm{l}$ of lysis solution (Tris- $\mathrm{HCl} 110 \mathrm{~mm}, \mathrm{pH} 8.9, \mathrm{MgCl}_{2} 1.5 \mathrm{~mm}, \mathrm{KCl} 80 \mathrm{~mm}$, BSA $500 \mu \mathrm{g} / \mathrm{ml}, 0.1 \%$ sodium cholate, $0.1 \%$ Triton X-100, Proteinase K $200 \mu \mathrm{g} / \mathrm{ml}, 0.45 \%$ Tween $20,0.45 \%$ Nonidet $\mathrm{p}-40$ ). Then the sample was incubated at $60^{\circ} \mathrm{C}$ for $20 \mathrm{~min}$ for destruction and proteolysis, at $95^{\circ} \mathrm{C}$ for $13 \mathrm{~min}$ to inactivate the Proteinase $\mathrm{K}$, and then cooled at $50^{\circ} \mathrm{C}$ for $5 \mathrm{~min}$.

PCR and Electrophoresis PCR was carried out to detect the presence of malaria parasites in mosquitoes. The sample was spun down and mixed with $10 \mu \mathrm{l}$ of PCR reagent mixture (Tris- $\mathrm{HCl} 10 \mathrm{~mm}, \mathrm{pH} 8.9, \mathrm{MgCl}_{2} 1.5 \mathrm{~mm}, \mathrm{KCl}$ $80 \mathrm{~mm}$, BSA $500 \mu \mathrm{g} / \mathrm{ml}, 0.1 \%$ sodium cholate, $0.1 \%$ Triton $\mathrm{X}-100,5 \mu \mathrm{g} / \mathrm{ml}$ primer, dNTPs $1 \mathrm{~mm}$ ). The mixture was spun down, vortexed, and subjected to 30 cycles. The conditions were as follows: denaturation at $92^{\circ} \mathrm{C}$ for $60 \mathrm{~s}$, annealing at $52^{\circ} \mathrm{C}$ for $90 \mathrm{~s}$, and extension at $72^{\circ} \mathrm{C}$ for $90 \mathrm{~s}$. The amplified DNA was denatured by heating at $95^{\circ} \mathrm{C}$ for $10 \mathrm{~min}$ and then rapid cooling on ice for $10 \mathrm{~min}$. Positive controls were DNA of $P$. falciparum, $P$. vivax, $P$ ovale, $P$. ovale-variant, and $P$. malariae from clinical patients. Sterilized water was used as a negative control. The PCR products $(10 \mu \mathrm{l})$ were electrophoresed at $100 \mathrm{~V}$ for $40 \mathrm{~min}$ using $1.2 \%$ agarose gel, stained by ethidium bromide, and the bands were visualized with a UV transillumintor.

Hybridization and Colorization of the MPH The procedure for hybridization and colorization in the MPH technique have been described previously. ${ }^{23,26,28)}$ Briefly, mi- crotiter plate wells are coated with probes specific for $P$. falciparum, $P$. vivax, $P$. ovale, and $P$. ovale-variant, and $P$. malariae was added at $100 \mu \mathrm{l} /$ well of $5 \times \mathrm{SSC}(1 \times \mathrm{SSC}$ is $\mathrm{NaCl} 0.15 \mathrm{~m}$ plus sodium citrate $0.015 \mathrm{~m}$ ) and $5 \mu \mathrm{l}$ of PCR product was added to the wells. Then the plate was incubated at $58^{\circ} \mathrm{C}$ for $1 \mathrm{~h}$, then the solution was removed, and the wells were washed three times with $250 \mu \mathrm{l} /$ well of $1 \times$ solution (Tris- $\mathrm{HCl} 0.1 \mathrm{M}, \mathrm{pH} 7.5, \mathrm{NaCl} 0.1 \mathrm{M}, \mathrm{MgCl}_{2} 2 \mathrm{~mm}, 0.05 \%$ Triton X-100). Then $100 \mu \mathrm{l}$ of alkaline phosphatase-labeled streptavidin was added and incubated at $28^{\circ} \mathrm{C}$ for $15 \mathrm{~min}$. After that the solution was removed and the well was washed three times with $250 \mu \mathrm{l} /$ well of $1 \times$ solution. Then $100 \mu \mathrm{l} /$ well of coloring substrate, PNPP solution (diethanolamine $1 \mathrm{M}, \mathrm{pH}$ $9.8, \mathrm{MgCl}_{2} 0.5 \mathrm{~mm}$, and para-nitrophenyl phosphate $10 \mathrm{~mm}$ ) were added and incubated at $28^{\circ} \mathrm{C}$ for $30 \mathrm{~min}$. The absorbance of each well was read at $405 \mathrm{~nm}$ using a microtiter plate reader (MPR-A4, Tosoh, Tokyo, Japan). The data were obtained by subtraction of the background corresponding to the PNPP solution. ${ }^{20)}$

\section{RESULTS}

Proportion of Anopheline Mosquitoes Mosquitoes were captured only one time from each household of two unions in Chakaria during June 2007. In this survey, a total of 868 mosquitoes were collected from the three villages in two unions. Among the total collected mosquitoes, 669 (77.1\%) mosquitoes were found to be female anopheline mosquitoes. The species of anopheline mosquitoes were morphologically identified as A. minimus, 651 (97.3\%); 18 $(2.7 \%)$ mosquitoes were other Anopheles species. The remaining $199(22.9 \%)$ of the total collected mosquitoes were Culex species. Among the 868 mosquitoes, 838 were collected from the village of Pahartoli (Table 1).

Table 1. The Number of Mosquito Collected from Chakaria, Bangladesh (12-30 June, 2007)

\begin{tabular}{|c|c|c|c|c|c|}
\hline \multirow[b]{2}{*}{$\begin{array}{l}\text { Union } \\
\text { name }\end{array}$} & \multirow[b]{2}{*}{$\begin{array}{l}\text { Village } \\
\text { name }\end{array}$} & \multicolumn{3}{|c|}{ Mosquito species } & \multirow[b]{2}{*}{$\begin{array}{l}\text { Total } \\
\text { No. }\end{array}$} \\
\hline & & $\begin{array}{c}\text { Anopheles } \\
\text { minimus }\end{array}$ & $\begin{array}{c}\text { Other } \\
\text { Anopheles } \\
\text { species }\end{array}$ & $\begin{array}{c}\text { Culex } \\
\text { species }\end{array}$ & \\
\hline Harvang & Goalmara & 0 & 4 & 17 & 21 \\
\hline \multirow[t]{2}{*}{ Kakhara } & Manikpur & 2 & 7 & 0 & 9 \\
\hline & Pahartoli & 649 & 7 & 182 & 838 \\
\hline Total & & $651(75.0 \%)$ & $18(2.1 \%)$ & $199(22.9 \%)$ & 868 \\
\hline
\end{tabular}

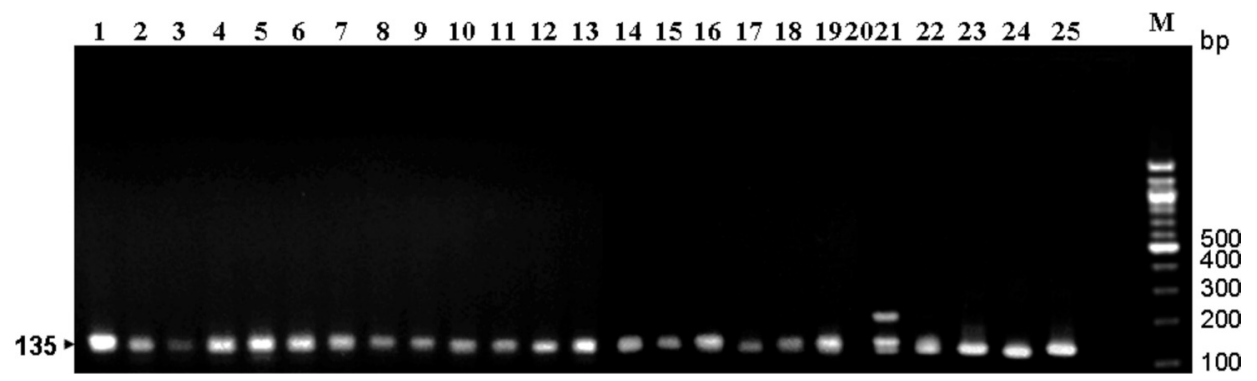

Fig. 2. Agarose Gel Electrophoresis Pattern Showing the Malaria Parasite-Positive PCR Product from $A$. minimus (Lanes $1-19$ ), Negative Control (Lane 20), and Positive Control with DNA of P. falciparum, P. vivax, P. ovale, P. ovale-variant, and P. malariae (Lanes 21-25)

M, DNA ladder marker of $100 \mathrm{bp}$. PCR products represent the results of only malaria parasite-positive mosquitoes; malaria parasite-negative mosquitoes are not included. 
Table 2. MPH Results of Mosquitoes Collected from Chakaria, Bangladesh (12-30 June, 2007)

\begin{tabular}{|c|c|c|c|c|c|c|}
\hline \multirow{2}{*}{ Village name } & \multirow{2}{*}{ Collection date } & \multirow{2}{*}{$\begin{array}{c}\text { Total } \\
\text { mosquito } \\
\text { No. }\end{array}$} & \multicolumn{3}{|c|}{ Plasmodium species $^{a)}$} & \multirow{2}{*}{$\begin{array}{c}\text { Total malaria } \\
\text { positive } \\
\text { No. }\end{array}$} \\
\hline & & & P.f. & P.v. & P.f. + P.v. & \\
\hline Goalmara & 15th June & 4 & - & - & - & - \\
\hline Pahartolir & 15th June & 25 & - & - & - & - \\
\hline Manikpur & 20th June & 9 & - & - & - & - \\
\hline Pahartoli & 21st June & 17 & - & - & - & - \\
\hline Pahartoli & 22nd June & 105 & 1 & - & - & 1 \\
\hline Pahartoli & 23rd June & 116 & 6 & 1 & 4 & 11 \\
\hline Pahartoli & 24th June & 85 & - & - & - & - \\
\hline Pahartoli & 25th June & 74 & 3 & - & 2 & 5 \\
\hline Pahartoli & 26th June & 84 & - & - & - & - \\
\hline Pahartoli & 27th June & 39 & - & - & - & - \\
\hline Pahartoli & 28th June & 24 & 1 & - & - & 1 \\
\hline Pahartoli & 29th June & 55 & - & - & - & - \\
\hline Pahartoli & 30th June & 32 & 1 & - & - & 1 \\
\hline Total & & 669 & 12 & 1 & 6 & 19 \\
\hline
\end{tabular}

a) Anopheles mosquitoes which were positive of malaria parasites were A. minimus.

Table 3. Absorbance Value of Malaria Parasite Positive Mosquitoes by MPH

\begin{tabular}{|c|c|c|c|c|c|c|c|}
\hline \multirow{2}{*}{ Mosquito no. } & \multirow{2}{*}{ Collection date } & \multicolumn{5}{|c|}{ Absorbance value at $405 \mathrm{~nm}^{a}$ ) } & \multirow{2}{*}{$\begin{array}{c}\text { Plasmodium } \\
\text { species }\end{array}$} \\
\hline & & P.f. & P.v. & P.o. & P.o-v. & P.m. & \\
\hline 1 & 22nd June & 0.625 & 0.005 & 0.008 & 0.007 & 0.007 & P.f. \\
\hline 2 & 23rd June & 0.468 & 0.011 & 0.011 & 0.005 & 0.011 & Pf. \\
\hline 3 & 23rd June & 0.304 & 0.675 & 0.000 & 0.000 & 0.006 & P.f. + P.v. \\
\hline 4 & 23rd June & 0.766 & 0.522 & 0.000 & 0.000 & 0.000 & P.f. + P.v. \\
\hline 5 & 23rd June & 0.780 & 0.986 & 0.004 & 0.000 & 0.000 & P.f. + P.v. \\
\hline 6 & 23rd June & 0.924 & 0.000 & 0.000 & 0.000 & 0.000 & P.f. \\
\hline 7 & 23rd June & 1.017 & 0.033 & 0.006 & 0.000 & 0.005 & P.f. \\
\hline 8 & 23rd June & 1.554 & 0.377 & 0.006 & 0.000 & 0.010 & P.f. + P.v. \\
\hline 9 & 23rd June & 1.121 & 0.080 & 0.019 & 0.000 & 0.022 & P.f. \\
\hline 10 & 23rd June & 0.000 & 0.392 & 0.003 & 0.000 & 0.005 & P.v. . \\
\hline 11 & 23rd June & 0.513 & 0.000 & 0.004 & 0.000 & 0.004 & Pf. \\
\hline 12 & 23rd June & 0.575 & 0.000 & 0.000 & 0.000 & 0.000 & P.f. \\
\hline 13 & 25th June & 0.539 & 0.554 & 0.004 & 0.010 & 0.009 & P.f. + P.v. \\
\hline 14 & 25th June & 0.336 & 1.208 & 0.005 & 0.004 & 0.018 & P.f. + P.v. \\
\hline 15 & 25 th June & 0.308 & 0.002 & 0.001 & 0.000 & 0.003 & P.f. \\
\hline 16 & 25th June & 0.612 & 0.002 & 0.006 & 0.000 & 0.019 & P.f. \\
\hline 17 & 25th June & 1.586 & 0.046 & 0.024 & 0.022 & 0.026 & P.f. \\
\hline 18 & 28th June & 1.370 & 0.020 & 0.019 & 0.017 & 0.012 & P.f. \\
\hline 19 & 30th June & 0.919 & 0.019 & 0.010 & 0.000 & 0.008 & P.f. \\
\hline
\end{tabular}

a) Blank average for all reactions was 0.123 and all positive results were two times higher than the blank average. P.f., Plasmodium falciparum; P.v., Plasmodium vivax; P.o., Plasmodium ovale, P.o.-v., Plasmodium ovale-variant; P.m., Plasmodium malariae.

Electrophoresis Results of PCR Product in Mosquitoes The extracted DNA of 669 mosquitoes was amplified using the primer pair set of MPH1 and MPH2 for detecting the malaria parasite. The amplified PCR product was subjected to agarose gel electrophoresis and this revealed a prominent band at 135 basepairs of malaria parasites in Anopheles mosquitoes. A total of 19 Anopheles mosquitoes were found to be malaria parasite positive (Fig. 2)

Results of MPH After PCR amplification, the PCR products were analyzed using the MPH technique. The total malaria parasite-positive rate was $2.8 \%(19 / 669)$ and it showed the same results as PCR. Among the 19 positive samples, $12(63.2 \%)$ were positive only against the $P$. falciparum probe and $1(5.3 \%)$ against the $P$. vivax probe. Six samples $(31.6 \%)$ showed strong positive reactions against both the $P$. falciparum and $P$. vivax probe. Malaria parasitepositive mosquitoes were all $A$. minimus species and all were collected from the village of Pahartoli. Eleven malaria parasite-positive mosquitoes were collected on June 23, five on June 25 , one on June 22, one on June 28, and one on June 30 (Table 2). The absorbance values of 19 samples of malariapositive mosquitoes using the MPH technique are listed in Table 3.

\section{DISCUSSION}

Malaria vector surveillance is a prerequisite for malaria vector control. When vector surveillance is carried out on large numbers of mosquitoes, they must be tested for the presence of parasites. Salivary gland dissection is impractical when processing large numbers of mosquitoes. ${ }^{17)}$ Moreover, microscopic examination is time-consuming and labor intensive and cannot distinguish between different species of malaria parasites. ${ }^{29)}$ On the other hand, MPH is very sensitive 
in distinguishing malaria parasite species. In Bangladesh, malaria is restricted to the hilly districts in the eastern and southern border areas. ${ }^{30}$ ) Very few studies have been carried out in Bangladesh on the population densities of Plasmodium sporozoite-infected mosquitoes, especially in the endemic area of Chakaria, and the malaria infection rate in mosquitoes has not been determined. Therefore we tried to determine the malaria vector population infected with malaria parasites responsible for malaria transmission in the highly endemic area of Chakaria, Bangladesh. In the area, mosquito collection was conducted in June 2007, when there was unusually heavy rainfall and most of the study area was under water. Therefore it was difficult to collect Anopheles mosquitoes from all three villages, and most mosquitoes were collected from the village of Pahratoli.

In our study using CDC light traps, $77.1 \%$ of mosquitoes collected were anopheline, of which $97.3 \%$ were $A$. minimus mosquitoes. In another study, the mosquitoes were collected using the human landing aspiration technique, the anopheline mosquito collection rate was $37.0 \%$, and among the Anopheles mosquitoes, A. minimus comprised $50 \%$ in the same area. ${ }^{7)}$ Other researchers reported that the $A$. minimus mosquito collection rate was $57.3 \%$ in the Chittagong Hill Tracts, which were also collected using human bait. ${ }^{31)}$ Data from our study suggest that rainfall may increase the Anopheles mosquito population. During the study, the Matamuhuri River surrounding the study area overflowed and may have increased the breeding area for A. minimus. The increase in population is related to the increase in breeding sites in which Anopheles eggs are deposited and develop into adults. Usually rainfall is associated with increased humidity that stimulates the resting gravid mosquitoes to oviposit and seek new hosts. In our study, the maximum number of mosquitoes was collected 2 weeks after the rainfall as it takes $10-14 \mathrm{~d}$ to mature after oviposition. The same result was found when numerous mosquitoes were concentrated in $2-4$ weeks after rainfall. ${ }^{32)}$

The sporozoite rate in mosquitoes can be detected using different methods such as the enzyme-linked immunosorbent assay (ELISA) and rapid dipstick immunochromatographic assay (Vec-Test Malaria). But ELISA requires training and with Vec-Test false-positive reactions may occur. ${ }^{33,34)}$ Nested PCR targeting 18S rRNA has also been used to detect malaria parasite infection in mosquitoes. ${ }^{16)}$ However, malaria parasites in mosquitoes are detected from a population pool, not from single mosquitoes, in these cases. Our study shows that malaria parasites can be identified from an individual female Anopheles using the MPH technique. Ninteen $(2.8 \%)$ mosquitoes were found to be malaria positive. All were $A$. minimus, and the malaria parasite species in these mosquitoes were distinguished into $12 P$. falciparum, one $P$. vivax, and six mixed infection with $P$. falciparum and $P$. vivax. It has been reported that mixed infection with $P$. falciparum and $P$. vivax was found in $A$. dirus, and mixed infection with P. falciparum and P. malariae was found in Anopheles funestus in Manchiana, Mozambique. ${ }^{35,36}$ Khan and Talibi reported that the $A$. minimus sporozite rate was $1.3 \%$ in the Chittagong Hill Tracts, Bnagladesh, ${ }^{31)}$ one of the hilly areas in Bangladesh, and the sporozoites of $A$. dirus were indistinguishable but were assumed to be $P$. vivax or $P$. falciparum. ${ }^{30)}$ Malaria parasite-positive mosquitoes were also found in
Chanpara, where the sporozoite rate was $2.3 \%$, and Bagadi and Barakanda, where the sporozoite rate was $1.4 \%$, all districts of in Dhaka. ${ }^{3,4)}$ In all cases, malaria parasites were detected by dissection of the salivary glands and parasite species were not identified. However, our study demonstrated that a simple technique can be used to isolate malaria parasite DNA from dried whole bodies of mosquitoes for PCR amplification and to distinguish malaria parasites using MPH. Therefore the MPH technique sensitively detects single and mixed infections with malaria parasites in Anopheles and both $P$. falciparum and $P$. vivax were predominant in the study area of Chakaria.

Our present findings show that 19 of 669 malaria parasitepositive Anopheles mosquitoes were detected, and that rate was higher than in the other study areas in Bangladesh. As malaria parasite DNA was extracted from the whole mosquitoes and not from the head and thorax, it cannot be confirmed that all the positive Anopheles mosquitoes could be involved in malaria parasite transmission. Further research may be required to detect malaria parasites-positive mosquitoes that can transmit malaria parasites. But our investigations revealed that the MPH technique is simple, sensitive, easy, and not time-consuming for malaria parasite detection in numerous mosquitoes. Our results also indicate that there may be a relation between rainfall and the $A$. minimus mosquito population. As one of the principal malaria vectors in Chakaria, $A$. minimus mosquitoes may play a greater role in malaria transmission in the area after heavy rainfall. Therefore special attention should be given to reducing the population of this mosquito for malaria control. This was the first report of distinguishing malaria parasites in individual female Anopheles mosquitoes using the MPH technique and also the first report of the malaria-positive rate in Anopheles in Chakaria, Bangladesh. The MPH technique is recommended for use in identifying malaria transmitters and in epidemiologic studies for promoting effective control measures not only for Bangladesh but also for other malaria-endemic areas. Our data will play an important role in initiating malaria control in Bangladesh.

Acknowledgments We thank Sk. Md. Shamsuzzaman and the field workers Md. Hamid, Md. Shahid, and staff of Chakaria Branch of the Centre for Health and Population Research ICDDR, B, Bangladesh for cooperating in this study. The ICDDR, B Research Centre support for this study is gratefully acknowledged. This work was supported in part by a Grant-in-Aid for Scientific Researchers on Priority Areas from the Ministry of Education, Culture, Sports, Science and Technology of Japan (19041049) and by the Programme for Promotion of Fundamental Studies in Health Sciences of the National Institute of Biomedical Innovation (NIBIO) (project no. 04-09, Yusuke Wataya).

\section{REFERENCES}

1) Levashina A. E., Insect Biochem. Mol. Biol., 34, 673-678 (2004).

2) Rahman A., Kogan F., Roytman L., Am. J. Trop. Med. Hyg., 74, 1719 (2006).

3) Maheswary N. P., Habib M. A., Elias M., Southeast Asian J. Trop. Med. Public Health, 23, 798-801 (1992).

4) Maheswary N. P., Khan Z., Molla F. R., Haq M. I., Southeast Asian J. Trop. Med. Public Health, 24, 776-778 (1993). 
5) Montanari R. M., Bangali A. M., Talukder K. R., Baqui A., Maheshwary N. P., Gosh A., Rahman M., Mahmood A. H., Bull. World Health Org., 79, 648-656(2001).

6) Van den Broek I. V., Van der Wardt S., Talukdar L., Chakma S., Brockman A., Nair S., Anderson T. C., Trop. Med. Int. Health, 9, 680-687 (2004).

7) ICDDR, B., Health Sci. Bull., 1, 10-14 (2003).

8) Blandin S. A., Levashina E. A., Curr. Opin. Immunol., 16, 16-20 (2004).

9) Ahmed T. U., Mosq. Sys., 19, 187-200 (1987).

10) Elias M., Dewan Z., Ahmed R., J. Prev. Soc. Med., 1, 20 (1982).

11) Lee H. W., Shin E., Cho S. H., Lee H., Kim C., Lee W., Moon S., Lee J., Lee W., Kim T., Korean J. Parasitol., 40, 75-81 (2002).

12) Mahapatra N., Marai N. S., Ranjit M. R., Parida S. K., Hansdah D. P. Hazra R. K., Kar S. K., J. Vector Borne Dis., 43, 191-194 (2006).

13) Stoffels J. A., Van Leeuwen W. M., Post R. J., Med. Vet. Entomol., 19, 433-437 (1995).

14) Moreno M., Cano J., Nzambo S., Bobuakasi L., Buatiche N. J., Ondo M., Micha F., Benito A., Malaria J., 3, 20 (2004)

15) Tassannakajon A., Boonsaeng V., Wilairat P., Panyim S., Trans. R. Soc. Trop. Med. Hyg., 87, 273-275 (1993).

16) Vythilingam I., Nitiavathy K., Yi P., Bakotee B., Hugo B., Singh B., Writz R. A., Palmer K., Southeast Asian J. Trop. Med. Public Health, 30, 631-635 (1999).

17) Santos-Ciminera P. D., Achee N. L., Quinnan J. R., Roberts D. R., J. Am. Mosq. Control Assoc., 20, 165-271 (2003).

18) Harada M., Ishikawa H., Matsuoka H., Ishii A., Suguri S., Acta Med. Okayama, 54, 165-171 (2000).

19) Ranford-Cartwright L. C., Balfe P., Carter R., Mol. Biochem. Parasitol., 49, 239-244 (1991).

20) Arai M., Kunisada K., Kawai S., Kimura M., Wataya Y., Nucleosides Nucleotides, 13, 1363-1374 (1994).

21) Kawamoto F., Miyake H., Kaneko O., Kimura M., Nguyen T. D., Nguyen T. D., Liu Q., Zhou M., Le D. D., Kawai S., Isomura S.,
Wataya Y., J. Clin. Microbiol., 34, $2287-2289$ (1996).

22) Laoboonchai A., Kawamoto F., Thanoosingha N., Kojima S., ScottMiller R. R., Kain K. C., Wongsrichanalai C., Trop. Med. Int. Health, 6, 458-462 (2001).

23) Chai J., Park Y., Guk S., Oh K., Oh M., Lee S., Kim H.-S., Wataya Y., Am. J. Trop. Med. Hyg., 63, 80-84 (2000).

24) Mboera L. E., Kihonda J., Braks M. A., Knols B. G., Am. J. Trop. Med. Hyg., 59, 595-596 (1998).

25) Ki J., Chang K., Roh H., Lee B., Yoon J., Jang G., J. Biosci. Bioeng., 103, 242-246 (2007).

26) Kimura M., Miyake H., Kim H.-S., Tanabe M., Arai M., Kawai S., Yamane A., Wataya Y., J. Clin. Microbiol., 33, 2342-2346 (1995).

27) Kawai S., Maekawajiri S., Yamane A., Anal. Biochem., 209, 63-69 (1993).

28) Arai M., Kunisada K., Kim H.-S., Miyake H., Mizukoshi C., Kakutani T., Yamane A., Nakagami S., Kawai S., Nakano H., Kawamoto F., Wataya Y., Nucleosides Nucleotides, 15, 719-731 (1996).

29) Li F., Niu C., Ye B., Chin. Med. J., 114, 654-657 (2001).

30) Rosenberg R., Maheswary N. P., Am. J. Trop. Med. Hyg., 31, 183-191 (1982).

31) Khan A. Q., Talibi S. A., Bull. World Health Org., 46, 783-792 (1972).

32) Oesterholt M., Bousema J. T., Mwerinde O. K., Harris C., Lushino P., Masakoto A., Mwerinde H., Mosha F. W., Drakely C. J., Malaria J., 5, 98 (2006).

33) Writz R. A., Burkot T. R., Andre R. G., Rosenberg R., Collins W. E., Roberts D. R., Am. J. Trop. Med. Hyg., 34, 1048-1054 (1985).

34) Ryan J. R., Dave K., Coleman R. E., Emmerich E., Sattabongkot J., Dunton R. F., Writz R. A., Med. Vet. Entomol., 15, 225-230 (2001).

35) Rosenberg R., Andre R. G., Somchit L., Trans. R. Soc. Trop. Med. Hyg., 84, 22-28 (1990).

36) Marques P. X., Saute F., Pinto V. V., Cardoso S., Pinto J., Alonso P. L., Rosario do V. E., Int. J. Biol. Sci., 2, 96-102 (2005). 